\title{
Optimisation of $\mathrm{CNC}$ routing operations of wooden furniture parts
}

\author{
Tomasz Gawroński
}

Received: 21 May 2012 / Accepted: 13 November 2012 / Published online: 20 December 2012

(C) The Author(s) 2012. This article is published with open access at Springerlink.com

\begin{abstract}
The aim of this paper is to develop mathematical model and computational procedure for optimisation of feed rate at CNC routing operations of wooden furniture parts. The proposed approach takes into consideration special characteristics of solid wood, like changes in cutting forces and obtained surface quality along with cutting direction. A multistage optimisation procedure is developed, which employs binary search method and genetic algorithm. Because of the problem of full specification of feasible region in the form of inequalities, a fuzzy logic is used for correction of intermediate results within computational procedure. The developed method is verified by optimisation of routing operation of a typical furniture part, i.e. commode top. As a result of optimisation, the processing time is reduced by $54 \%$.
\end{abstract}

Keywords Furniture $\cdot \mathrm{CNC}$ routing $\cdot$ Optimisation .

Wood · Processing time

\section{Notation}

$A_{i} \quad$ cross section area of layer or profile being cut at micro-segment $i$

$c_{k \|} \quad$ correction coefficients $(k=1, \ldots, 7)$ for $\kappa_{\|}$,

$c_{k \#} \quad$ correction coefficients $(k=1, \ldots, 7)$ for $\kappa_{\#}$,

$c_{k \perp} \quad$ correction coefficients $(k=1, \ldots, 7)$ for $\kappa_{\perp}$,

$f_{i} \quad$ feed rate at micro-segment $i$,

$\widehat{f_{i}} \quad$ optimised feed rate at micro-segment $i$,

$\tilde{f_{i}} \quad$ feed rate after correction at micro-segment $i$,

$f_{j}^{\prime} \quad$ feed rate at final segment $j$,

T. Gawroński $(\bowtie)$

Department of Furniture Design, Poznań University

of Life Sciences, Wojska Polskiego 28, 60-637 Poznań, Poland

e-mail: tgawronski@up.poznan.pl
$f_{T}^{\max }$

$f_{M(x)}^{\max }$

$\mathrm{X}$ axis,

$f_{M(y)}^{\max }$ maximum feed rate available at machine along Y axis,

$f_{M(z)}^{\max }$ maximum feed rate available at machine along $\mathrm{Z}$ axis,

$\mathbf{F}_{i} \quad$ unit feed vector at micro-segment $i$,

$g \quad$ chip thickness,

$i \quad$ index of micro-segment,

$j \quad$ index of final segment,

$J_{i} \quad$ binary decision variables for joining of microsegments,

$l_{j} \quad$ length of final segment $j$,

$n$ number of micro-segments,

$n^{\prime} \quad$ number of final segments,

$n_{0} \quad$ number of initial segments,

$P \quad$ machine's main motor power,

$p \quad$ penalty function,

$q$ fitness function,

$S_{i} \quad$ micro-segment $i$,

$t$ processing time,

$w \quad$ cutting width,

$W_{i \|} \quad$ component of wood fibre vector in the direction within cutting plane perpendicular to cutting edge,

$W_{i \#} \quad$ component of wood fibre vector in the direction along cutting edge,

$W_{i \perp} \quad$ component of wood fibre vector in the direction perpendicular to cutting plane,

$\alpha \quad$ code size ratio,

$\beta \quad$ penalty function coefficient,

$\gamma_{1} \quad$ strength of membership function for do-not-slowdown action,

$\gamma_{2}$ strength of membership function for slow-down action, 
$\delta_{i} \quad$ feed per tooth at micro-segment $i$,

$\Delta_{f} \quad$ assumed accuracy of determination of $\widehat{f_{i}}$,

$\varepsilon \quad$ tool attack angle,

$\eta \quad$ mechanical efficiency of machine's main drive,

$\kappa_{i} \quad$ specific cutting power at micro-segment $i$,

$\kappa_{\|} \quad$ specific cutting power for typical cutting conditions along wooden fibres,

$\kappa \# \quad$ specific cutting power for typical cutting conditions across wooden fibres,

$\kappa_{\perp} \quad$ specific cutting force for typical cutting conditions perpendicular to wooden fibres,

$\mu_{\varphi c}^{B} \quad$ membership function of fuzzy set bad cutting edge direction angle,

$\mu_{\varphi f}^{B} \quad$ membership function of fuzzy set bad feed direction angle,

$\mu_{\varphi c}^{G} \quad$ membership function of fuzzy set good cutting edge direction angle,

$\mu_{\varphi f}^{G} \quad$ membership function of fuzzy set good feed direction angle,

$\varphi_{c} \quad$ angle between cutting edge and wood fibres,

$\varphi_{f} \quad$ angle between feed direction and wood fibres.

\section{Introduction}

In modern furniture industry, $\mathrm{CNC}$ working centres are widely used, especially when high quality of product and flexibility of manufacturing process are expected. Even though there are many advanced computer-aided manufacturing systems for furniture producers, some technological parameters, like feed rates, must still be established arbitrarily. It seems that, in case of sophisticated solid wood furniture parts, there is general tendency to use low feed rates to guarantee high quality and to be sure that machine and tool limitations are satisfied. These practices are not always rational because of high processing times and, as a consequence, high manufacturing cost. Therefore, there is a need for an optimisation software that would allow for reduction of processing times under proper technological conditions.

The problem of CNC operation optimisation in metalworking has been well explored in the literature. Many researchers concentrate on the determination of optimal cutting speed and feed rate at milling [1, 21, 27, 30, 31, 33]. In the above-mentioned papers, these parameters are assumed to be constant for particular operation and part. On the contrary, variable federate is taken into consideration in [13, 25]. In turn, [23, 34] focus on CNC turning, adopting cutting speed, feed rate and depth of cut as decision variables, whereas $[2,32]$ consider constant depth of cut for the same operation. There are also various solution to the problem of optimal tool path during routing and turning $[3,4,14,15$,
28]. All of above cited papers involve numerical optimisation which is done prior to the processing of parts, so all processing parameters and processing times are known in advance.

On the contrary, there are no published research that address similar issues in case of solid wood processing. Moreover, because solid wood is a highly anisotropic material of specific fibrous structure, most of the methods developed for metalworking optimisation cannot be easily adopted. Some papers in this field applicable to furniture industry are $[17,20]$, which assume medium-density fibreboard as material to be processed. In the area of solid wood processing, numerical optimisation has been proposed for through feed operations like ripsawing and four-side planning [8]. However, because of constant feed rate and feed direction, through feed operations are much simpler than $\mathrm{CNC}$ operations. There are promising solutions dedicated to CNC operations in solid wood working $[6,10]$, which involve on-line feed rate adaptation based on monitoring of acoustic emission. While, generally, on-line adaptation of processing parameters may outperform ahead-of-time optimisation, it also has some significant drawbacks. First of all, it requires additional monitoring equipment and modification of $\mathrm{CNC}$ control system. Moreover, if a company uses enterprise resource planning software, the processing times should be known in advance. Another approach involves experimental determination of optimal machining parameter for particular wood species, equipment and parts to be processed $[22,26]$. However, the application of that approach is very limited when the above conditions change frequently.

The above literature review indicates the need for research on $\mathrm{CNC}$ operation optimisation dedicated to solid wood furniture production. Among routing and turning operations, the former seems to be more popular in the furniture industry, and, therefore, it should be of primary interest in the research.

The aim of this paper is to develop mathematical model and computational procedure for optimisation of feed rate at $\mathrm{CNC}$ routing operations of wooden furniture parts. The proposed method is designed to apply modification to CNC programme, before actual processing of parts, without the need for further on-line readjustments.

\section{General assumptions}

In the furniture production, a vast majority of routing can be performed with three-axis routers, and therefore, this type of CNC machines dominates in that industry. Thus, current research has been limited to three-axis CNC routers. 
Because of high anisotropy of solid wood, cutting force changes along with cutting direction. Moreover, it has been proved that the angle between feed and fibre direction has significant impact on routing quality [7, 11]. Therefore, the effective optimisation of such operations requires consideration of variable feed rate.

The tool path in CNC operations consist of segments that are simple geometrical primitives (lines, circles, arcs). When tool radius compensation is turned off, each of the primitives is a result of single movement instruction in $\mathrm{CNC}$ programme (G-code). It is very likely to happen that cutting conditions (cutting depth, feed direction) change within a segment. On the other hand, typical G-code allows for setting only one nominal constant feed rate for each segment. Therefore, it may be reasonable to divide long segments into smaller parts to allow more frequent federate change. However, the excessive division of segments produces long CNC programmes that may be difficult to handle by the code interpreter. Moreover, very frequent nominal feed rate changes are not rational. It is due to the fact that $\mathrm{CNC}$ controller must obey maximum acceleration and deceleration when establishing actual velocity of movement. Therefore, it may happen, especially for short segments and at rapid federate change, that the nominal value of this parameter is never reached. Thus, an optimisation software must find a trade-off between keeping nominal feed rate as high as possible and limiting the size of G-code.

In metalworking, $\mathrm{Li}$ et al. [13] divide original segments (resulting from G-code) into micro-segments of length about $2 \mathrm{~mm}$. The micro-segments are used for frequent verification of limiting conditions along the tool path. Then, neighbouring micro-segments are grouped together into final segments to decrease output code size. The nominal feed rate for final segments is set to satisfy constraints for each underlying micro-segment. The grouping is done with heuristic method, which requires further assumptions and does not guarantee finding optimum. In woodworking, due to the anisotropy of the material, the higher variability of cutting conditions may be expected. Therefore, establishing of effective parameters for heuristic grouping rules may be problematic. In this study, the above conception of division of original segments into micro-segments is also employed. However, the grouping of micro-segments into final segments is done with discrete optimisation method that requires fewer arbitrary parameters and that should be more likely to find global optimum.

The quality of peripheral milling is usually controlled by putting constraints on feed per tooth or calculated depth of waviness. However, in this way, the orientation of wooden fibres relative to feed direction is neglected. The above approach is satisfactory when feed direction is along wooden fibres, so the cutting conditions are gener- ally advantageous. In CNC routing, when the feed direction varies, significant changes in obtained surface roughness can be expected at the same feed per tooth. Unfortunately, in the literature, there is not enough data to develop a mathematical model that would take into account the influence of fibre orientation relatively to feed direction on acquired surface properties. However, based on [7, 11], it is possible to select places along the tool path, where feed rate should be decreased to maintain cutting quality. Because the conditions of operation to be optimised may be significantly different from the conditions of the above research, the available data should be treated as showing general tendencies rather than particular threshold values. Therefore, the feasible region cannot be fully defined by a set of inequalities as it is expected in case of numerical optimisation.

Because of the problem with direct formulation of mathematical model, it was decided to employ both numerical methods and fuzzy logic for the optimisation. The use of fuzzy logic should allow for generalisation of available experimental data within the optimisation model. The overview of proposed algorithm is presented in Fig. 1. For each micro-segment, a suboptimal feed rate is first determined, taking into consideration only these constraints that can be expressed with inequalities. Then, the suboptimal feed rate is corrected using fuzzy rules. Finally, the optimisation of final segments with the objective to minimise the output code size is performed.

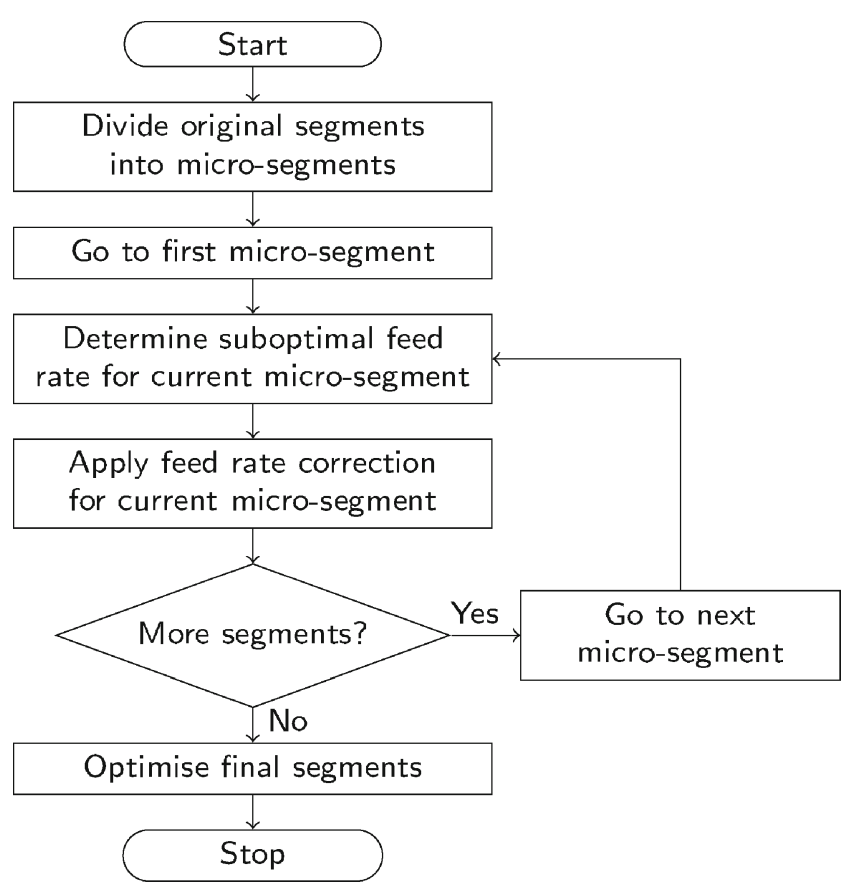

Fig. 1 Overview of proposed algorithm 


\section{Mathematical models and optimisation methods}

\subsection{Specific cutting power model}

One of the most important limitations of feed rate results from wood cutting forces and the power of main drive.

Although there is a significant number of more recent research on wood cutting forces (e.g. [5, 16, 19]), it seems that one of the most widely applicable methods for calculating specific power when cutting wood is the one proposed by Manshoz [18]. This method is intended to provide solution for a high variety of cutting conditions. Manshoz's approach has been used in more contemporary research [12], giving calculation results that are consistent with experiment.

Manshoz's method relies on basic specific cutting power values for cutting along main anatomical directions of wood in assumed typical circumstances and series of correction coefficients that consider the effect of particular cutting conditions, that may differ from that assumed as typical. Therefore $\kappa_{i}$ can be determined as follows:

$\kappa_{i}=W_{i \|}^{2} \kappa_{\|} \prod_{k} c_{k \|}+W_{i \#}^{2} \kappa \# \prod_{k} c_{k \#}+W_{i \perp}^{2} \kappa_{\perp} \prod_{k} c_{k \perp}$

In case of routing, particular $c_{k}$ coefficients reflect the influence of the following factors: wood species $\left(c_{1}\right)$, wood moisture content $\left(c_{2}\right)$, tool attack angle $\left(c_{3}\right)$, chip thickness $\left(c_{4}\right)$, tool dullness $\left(c_{5}\right)$, wood temperature $\left(c_{6}\right)$, as well as friction between wood and cutting edge $\left(c_{7}-\right.$ significant for full immersion routing only). These coefficients, as tabular data and/or experimental formulas together with basic values of specific cutting power are available in literature [18].

One of typical circumstances assumed by Manshoz [18] are wood species-pine, wood moisture content of $13 \%$, tool attack angle of $60^{\circ}$, chip thickness of $0.15 \mathrm{~mm}$, tool dullness-sharp and wood temperature of $20{ }^{\circ} \mathrm{C}$. If the above conditions are met, the specific cutting power for individual directions, determined experimentally is $\kappa_{\|}=$ $21.57 \mathrm{MJ} / \mathrm{m}^{3}, \kappa_{\#}=11.77 \mathrm{MJ} / \mathrm{m}^{3}$ and $\kappa_{\perp}=51.98 \mathrm{MJ} / \mathrm{m}^{3}$ $[18,24]$. In such case, all $c_{k}$ coefficients equal 1 .

According to Manshoz [18], the following values of $c_{1 \| \# \perp}$ should be selected for wood species other than pine: 1.0 for alder, 1.3-1.5 for beech, and 1.5-1.6 for oak. These values are correlated to wood density and are independent of cutting direction. In the case of dry wood (moisture content about $10 \%$ ) the influence of moisture on cutting force can be neglected. The same applies to wood temperature, since the mechanical processing of dried wood is performed in room temperature after conditioning of material. In turn, the influence of attack angle can be evaluated using the following experimental formulas, which are established based on tabular data available in [18] (for $\varepsilon$ in degrees):

$c_{3 \|}=0.236 \mathrm{e}^{0.0244 \varepsilon}$

$c_{3 \#}=0.622 \mathrm{e}^{0.00811 \varepsilon}$

$c_{3 \perp}=0.149 \mathrm{e}^{0.0321 \varepsilon}$

The correction coefficients that reflect the influence of chip thickness, for $g$ expressed in millimetres can be calculated as follows [18, 24]:

$c_{4 \|}=\left(\frac{0.15}{g}\right)^{0.47}$

$c_{4 \#}=\left(\frac{0.15}{g}\right)^{0.52}$

$c_{4 \perp}=\left(\frac{0.15}{g}\right)^{0.41}$

For sharp cutting tools (edge roundness radius 2-10

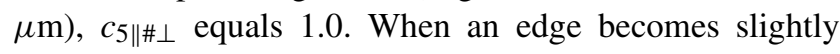
dull (roundness radius $46-50 \mu \mathrm{m}$ ), $c_{5 \| \# \perp}$ should be set to 1.5 [18].

Based on handbook recommendations and experimental data $[18,24]$, the following formula for evaluation on the influence of friction on cutting force during full immersion routing can be established:

$c_{7 \| \# \perp}=\left\{\begin{array}{lll}1 & \text { for } & w \leq 10 \mathrm{~mm} \\ 0.214 \ln (w)+0.498 & \text { for } & w>10 \mathrm{~mm}\end{array}\right.$

During formation of a single chip, due to rotation of a tool, the relation between cutting plane and wood fibre direction is changing. Therefore, the mean value of $\kappa_{i}$ should be determined. In case of partial immersion, machining components $W_{i \|}, W_{i \#}, W_{i \perp}$ are computed for the cutting edge position half way between entrance into and exit from material. In turn, for full immersion machining, according to the recommendation of [18], it is assumed that $\kappa_{i}$ does not depend on feed direction, and components $W_{i \|}, W_{i \#}$, $W_{i \perp}$ have been calculated at an angle between wood fibre direction and cutting plane equal $45^{\circ}$.

\subsection{Suboptimisation of feed rate}

The mathematical model for the optimisation of feed rate can be defined as follows:

Find

$\widehat{f_{i}}=\max \left(f_{i}\right)$ 
subject to the following constraints:

Tool constraint:

$f_{i} \leq f_{T}^{\max }$

Machine's support drive constraints:

$$
\begin{gathered}
f_{i} F_{i x} \leq f_{M(x)}^{\max } \\
f_{i} F_{i y} \leq f_{M(y)}^{\max } \\
f_{i} F_{i z} \leq f_{M(z)}^{\max }
\end{gathered}
$$

Machine's motor power constraint:

$$
f_{i} A_{i} \kappa_{i} \leq P \eta
$$

Feed per tooth constraint:

$\delta_{i} \leq 0.8 \mathrm{~mm}$

Determination of $A_{i}$ for routing with profiled tools is done by discretisation of curvilinear shape of cutting edge into a set of straight lines. It allows for simplification of input data and for fast and seamless simulation of cutting conditions at different radial and axial depth of cut. It is assumed that the cross-section area of real and discretised profile cannot differ more than by $1 \%$.

Because of the simple form of objective function 9, finding optimal value is equivalent to the determination of upper boundary of feasible range of $f_{i}$. For this, the binary search method is employed. The optimisation procedure for each micro-segment comprises the following steps:

1. Let $f_{i}^{A}=0, f_{i}^{B}=f_{T}^{\max }$ and $f_{i}=f_{T}^{\max }$.

2. If $f_{i}$ fulfils all constraints, then let $\widehat{f_{i}}=f_{i}$ and terminate procedure.

3. Let $f_{i}=\left(f_{i}^{A}+f_{i}^{B}\right) / 2$.

4. If $f_{i}$ fulfils all constraints, then let $f_{i}^{A}=f_{i}$; else, let $f_{i}^{B}=f_{i}$

5. If $f_{i}^{B}-f_{i}^{A}>\Delta_{f}$ then: go back to step 3

6. Let $\widehat{f_{i}}=f_{i}^{A}$ and terminate procedure.

\subsection{Correction of feed rate}

Based on [7, 11], bad cutting condition can be expected at an angle $\varphi_{f}$ between feed direction and wood fibres within the range $\left(0^{\circ}, 90^{\circ}\right)$ (Fig. 2$)$. The above circumstances result in high surface roughness that can be lowered through the reduction of feed rate. Conditions of $\varphi_{f}=0^{\circ}, \varphi_{f} \geq 90^{\circ}$ are very beneficial and show similar effect on surface quality. The worst value of $\varphi_{f}$ depends on wood species, but it generally can be expected between $15^{\circ}$ and $75^{\circ}$.

Moreover, [11] studies the effect of the fibre slope angle on surface roughness. Using tool-centric coordinate system, the slope equals $90^{\circ}-\varphi_{c}$, where $\varphi_{c}$ is an angle between

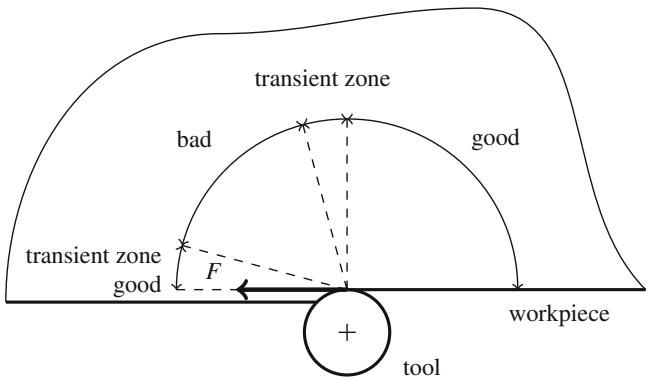

Fig. 2 Expected surface quality at various fibre orientation during cutting

cutting edge and wood fibres at the moment when cutting edge enters material. The above-cited research show that, generally, quality increases with $\varphi_{c}$ value.

The above analysis allows for the formulation of fuzzy sets that represents badness of $\varphi_{f}$ and $\varphi_{c}$ angles:

$\mu_{\varphi f}^{B}=\left(\varphi_{f}\right)\left\{\begin{array}{cl}\frac{\varphi_{f}}{15^{\circ}} & \text { for } \varphi_{f}<15^{\circ} \\ 1 & \text { for } 15^{\circ} \leq \varphi_{f}<75^{\circ} \\ \frac{90^{\circ}-\varphi_{f}}{15^{\circ}} & \text { for } 75^{\circ} \leq \varphi_{f}<90^{\circ} \\ 0 & \text { for } \varphi_{f} \geq 90^{\circ}\end{array}\right.$

$\mu_{\varphi_{c}}^{B}\left(\varphi_{c}\right)=\frac{90^{\circ}-\varphi_{c}}{90^{\circ}}$

where: $\varphi_{f} \in\left\langle 0^{\circ}, 180^{\circ}\right\rangle$ and $\varphi_{c} \in\left\langle 0^{\circ}, 90^{\circ}\right\rangle$.

The above membership function are presented in Fig. 3.

For the representations of good conditions, the complement operators are used:

$\mu_{\varphi_{f}}^{G}\left(\varphi_{f}\right)=1-\mu_{\varphi_{f}}^{B}\left(\varphi_{f}\right)$

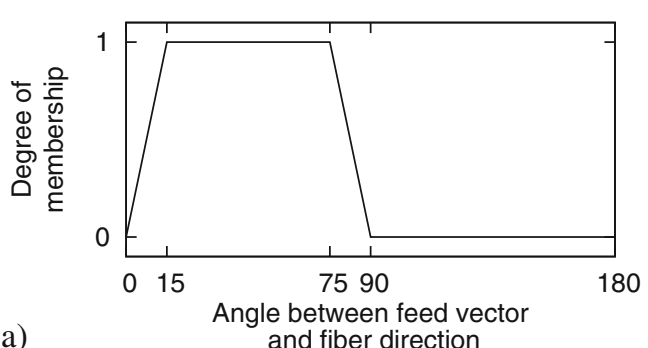

a)

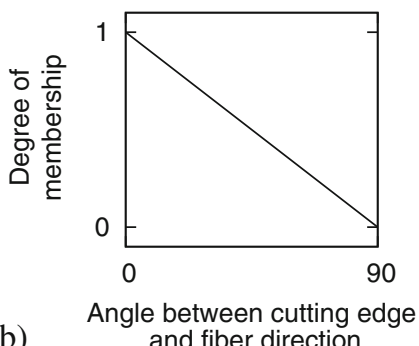

Fig. 3 Membership functions. a Bad feed direction angle. b Bad blade direction angle 
$\mu_{\varphi_{c}}^{G}\left(\varphi_{c}\right)=1-\mu_{\varphi_{c}}^{B}\left(\varphi_{c}\right)$.

Furthermore, the rules for the correction of feed rate are formulated in the form of fuzzy associative matrix (Table 1). Based on these rules, the corrected feed rate $\widetilde{f}_{i}$ is adjusted to be within the range $\left\langle f_{i}^{\min }, \widehat{f_{i}}\right\rangle$, where $f_{i}^{\min }$ is a feed rate for which $\delta=0.2 \mathrm{~mm}$. This is the lowest feed per tooth value recommended by some tool producers for routing with profiling tools.

Adopting Zadeh minimum operator as AND operator and employing root sum square method, the strength of membership functions for do-not-slow-down $\left(\gamma_{1}\right)$ and slow-down $\left(\gamma_{2}\right)$ actions can be determined as follows:

$$
\begin{aligned}
\gamma_{1}\left(\varphi_{f}, \varphi_{c}\right)= & \min \left(\mu_{\varphi_{f}}^{G}\left(\varphi_{f}\right), \mu_{\varphi_{c}}^{G}\left(\varphi_{c}\right)\right), \\
\gamma_{2}\left(\varphi_{f}, \varphi_{c}\right)= & \left(\left(\min \left(\mu_{\varphi_{f}}^{B}\left(\varphi_{f}\right), \mu_{\varphi_{c}}^{B}\left(\varphi_{c}\right)\right)\right)^{2}\right. \\
& +\left(\min \left(\mu_{\varphi_{f}}^{G}\left(\varphi_{f}\right), \mu_{\varphi_{c}}^{B}\left(\varphi_{c}\right)\right)\right)^{2} \\
& \left.+\left(\min \left(\mu_{\varphi_{f}}^{B}\left(\varphi_{f}\right), \mu_{\varphi_{c}}^{G}\left(\varphi_{c}\right)\right)\right)^{2}\right)^{\frac{1}{2}} .
\end{aligned}
$$

With the use of centre average deffuzification method, the corrected feed rate can be determined as follows:

$\widetilde{f_{i}}=\frac{\widehat{f_{i}} \gamma_{1}\left(\varphi_{f}, \varphi_{c}\right)+f_{i}^{\min } \gamma_{2}\left(\varphi_{f}, \varphi_{c}\right)}{\gamma_{1}\left(\varphi_{f}, \varphi_{c}\right)+\gamma_{2}\left(\varphi_{f}, \varphi_{c}\right)}$

In typical three-axis routing of wooden parts, the tool axis is perpendicular to wood fibres. In case of shaping tools, at each micro-segment, the worst (i.e. the lowest) $\varphi_{c}$ should be selected among values computed for each linear section of dicretised tool profile that does actual cutting.

\subsection{Optimisation of final segments}

As assumed before to reduce size of output CNC code, some subsequent micro-segment should be joined to form larger segments of constant feed rate. For that purpose, the following decision variables were designated:

$J_{i}=\left\{\begin{array}{l}0 \text { when } S_{i} \text { and } S_{i+1} \text { should be joined } \\ 1 \text { when } S_{i} \text { and } S_{i+1} \text { should not be joined }\end{array}\right.$

where $i=1, \ldots, n-1$.

Table 1 Fuzzy associative matrix

\begin{tabular}{lll}
\hline Linguistic variables & \multicolumn{2}{l}{ Feed direction angle } \\
\cline { 2 - 3 } & Good & Bad \\
\hline Cutting edge direction angle & & \\
Good & Do not slow down & Slow down \\
Bad & Slow down & Slow down \\
\hline
\end{tabular}

In order to maintain geometrical consistency of the solution, micro-segments $i$ and $i+1$ that belong to different original segments cannot be combined within one final segment. In case of such pair of micro-segments, $J_{i}$ is kept constant and equal 1 .

To ensure that constraints are met for all micro-segment, the feed rate for $j$-th final segment should be equal:

$f_{j}^{\prime}=\min _{S_{i} \in S_{j}^{\prime}}\left\{\tilde{f}_{i}\right\}$

Then, the optimisation problem can be defined as follows:

minimise:

$t=\sum_{j=1}^{n^{\prime}} \frac{l_{j}}{f_{j}^{\prime}}$

subject to the constraint:

$n^{\prime} \leq \alpha n_{0}$

where $\alpha$ is an arbitrary chosen ratio that limits the CNC code size increase.

Because of the binary type of decision variables, a genetic algorithm has been employed for the optimisation. The violation of constraint 26, to some extent, does not impose direct risk on the process. Therefore, this constraint is going to be applied in the algorithm as the following penalty function:

$p=\beta\left(\max \left(0, n^{\prime}-\alpha n_{0}\right)\right)^{2}$

Consequently, the following fitness function has been assumed:

$q=-t-p$.

Based on literature studies [3, 9, 23, 29, 33] and some preliminary test of optimisation software, the following conditions were assumed:

- population size: 200,

- total number of generations: 200,

- probability of crossover: 0.9 ,

- probability of mutation: 0.01 ,

- penalty function coefficient: 0.01 ,

- selection method: tournament,

- number of game participants: 4 .

During an initial test, the value of $\alpha$ coefficient was set to 10. It was observed that the lower values required increase of population size or the number of generations to find feasible solution, whereas higher values did not improve the obtained results (differences in processing time below $1 \%$ ). 


\section{Verification procedure}

In order to test the proposed method, the routing operation of commode top (Fig. 4) is optimised. It is assumed that this part is made of glued solid oak wood, and the fibre direction is along longer edge. The routing operation consist of two parts: sizing of part leaving 1-mm allowance for further processing and milling of edge profile (Fig. 4b). The tool paths for subsequent parts of the operation are presented in Fig. 5 .

Furthermore, the following assumptions have been made:

- machine's main motor power: $9 \mathrm{~kW}$

- main drive's mechanical efficiency: $98 \%$

- maximum available feed rate along machine axes: $X$ : $80 \mathrm{~m} / \mathrm{min}, \mathrm{Y}: 80 \mathrm{~m} / \mathrm{min}, \mathrm{Z}: 30 \mathrm{~m} / \mathrm{min}$

- allowance for sizing: $4 \mathrm{~mm}$ (per one side)

- sizing tool parameters: diameter, $20 \mathrm{~mm}$; maximum feed, $25 \mathrm{~m} / \mathrm{min}$; number of blades, 3; clearance angle, $10^{\circ}$; sharpness angle, $65^{\circ}$; blade inclination angle, $16^{\circ}$

- shaping tool parameters: diameter, $120 \mathrm{~mm}$; maximum feed, $20 \mathrm{~m} / \mathrm{min}$; number of blades, 4; clearance angle, $15^{\circ}$; sharpness angle, $45^{\circ}$; blade inclination angle, $0^{\circ}$

- tool dullness: slightly dull, i.e. $c_{5}=1.5$ (takes into account regular tool wear-out).

Due to the lack of particular quality requirements in case of sizing, the fuzzy feed rate correction and constraint 15 is disabled for this part of operation.

The effectiveness of the proposed method is evaluated by comparing processing time with and without optimisation. For nonoptimised operation, the maximum constant feed rate that satisfies all limiting condition along the path for a tool is assumed. This reflects the current approach in industry, where a constant, reasonable, feed rate is selected based on long-term experience.

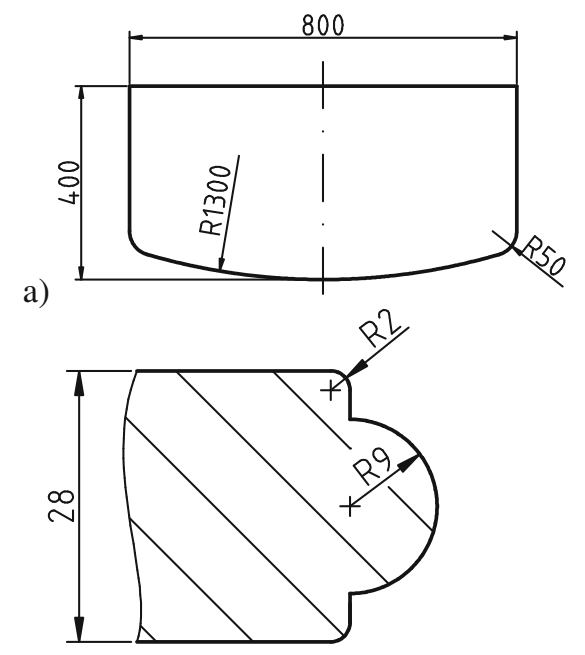

b)

Fig. 4 Furniture part used in verification procedure. a Top view. b Front and side edge profile a)

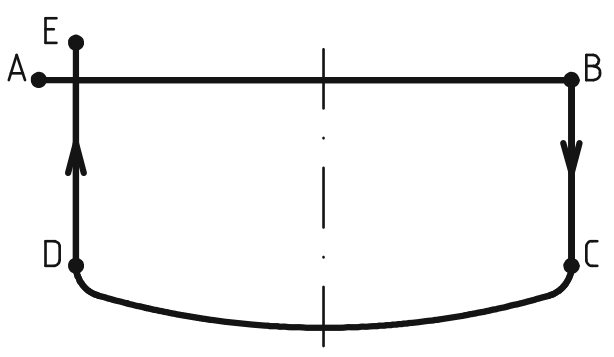

b)

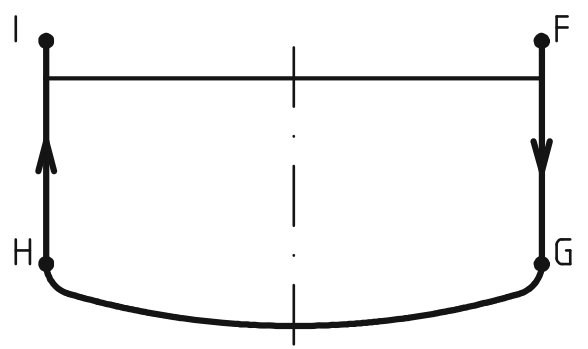

Fig. 5 Tool paths at routing operation. a Sizing. b Edge profiling

\section{Results}

Processing time of operation and number of segments in $\mathrm{CNC}$ code without and with optimisation is presented in Table 2. Proposed method allowed for $54 \%$ reduction of processing time. At the same time, code size is increased to the number, which is one segment more than the maximum assumed number of segments. This is due to the nature of penalty function, which, unlike barrier method, does not strictly forbid crossing boundary condition.

Figure 6 shows the feed rate before and after optimisation. The corresponding cutting power is plotted in Fig. 7. The highest optimised feed rate for sizing is achieved between points A and B, i.e. where cutting is done nearly along fibres and only small 4-mm allowance is removed. In this section, the cutting power is far below the machine's limit, so the only limiting constraint is the maximum feed rate for the tool. Changing of feed direction between points $\mathrm{B}$ and $\mathrm{C}$ as well as D and $\mathrm{E}$, at the same width and depth of cut, requires reduction of feed rate due to the cutting power limitations. The lowest optimised feed rate for sizing is between points $\mathrm{C}$ and $\mathrm{D}$, where the tool enters full immersion milling. The observed slight difference between

Table 2 Values of selected parameters without and with optimisation

\begin{tabular}{llll}
\hline Parameter & Unit & Value & \\
\cline { 3 - 4 } & & $\begin{array}{l}\text { Without } \\
\text { optimisation }\end{array}$ & $\begin{array}{l}\text { With } \\
\text { optimisation }\end{array}$ \\
\hline Processing time & min & 1.56 & 0.72 \\
Number of segments & - & 17 & 171 \\
\hline
\end{tabular}




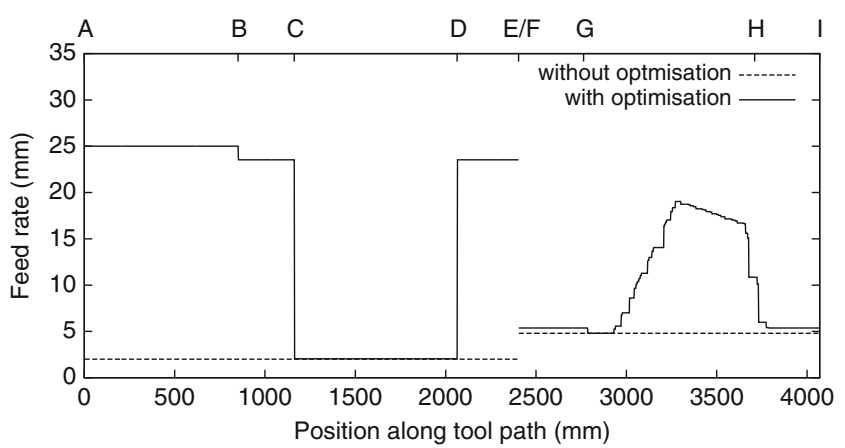

Fig. 6 Feed rate

obtained cutting power and cutting power limit (Fig. 7) is the result of assumed accuracy of feed rate optimisation $\left(\Delta_{f}\right)$.

In turn, for the assumed conditions of profile milling, the cutting power never reaches its upper limit. Therefore, the feed rate is only affected by the quality constraints. The changes of feed rate and cutting power between points $F$ and I (Figs. 6 and 7) reflect the acceleration and deceleration of tool in transient zones of fuzzy membership functions. To simplify analysis, membership functions that show badness of cutting conditions were plotted against the position along tool path (Fig. 8), maintaining the same $\mathrm{x}$-axis scale and range as in Figs. 6 and 7. Between points $F$ and $G$ as well as $\mathrm{H}$ and $\mathrm{I}$, the degree of badness of feed direction is 0 , while badness of blade direction angle is nearly 1 . Therefore, the feed rate within these sections is kept low. After crossing of point $\mathrm{G}$, badness of feed direction angle raises rapidly, while blade direction angle begins to improve. Because of the rapid increase of bad feed direction angle membership function, the feed rate is lowered to the minimum value. Then, both analysed membership function steadily decrease which results in the increase of feed rate and cutting power. The step-like shape of feed rate plot is a result of micro-segment concatenation. The best cutting conditions are exactly in the middle between points $\mathrm{G}$ and $\mathrm{H}$, which is reflected by the highest value of feed rate for profile milling. After that

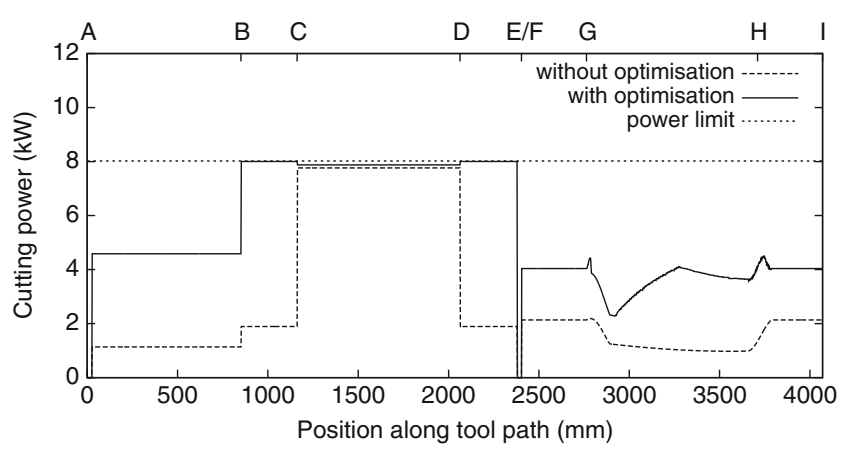

Fig. 7 Cutting power

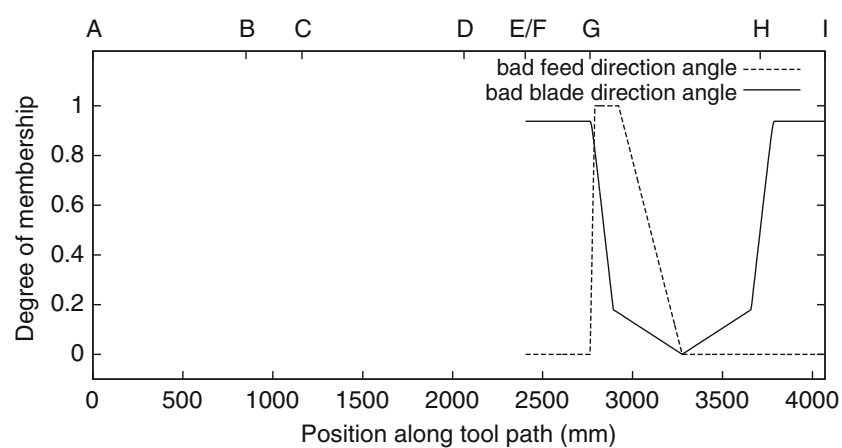

Fig. 8 Cutting conditions

point, feed rate begins to decrease due to the increasing degree of badness of blade direction angle.

Since the development of the above optimisation model that is based only on literature studies, there is a need for further experimental verification of obtained results. It is possible that experiments may reveal the need for additional constraint to ensure high cutting quality. However, specification of quality conditions in the form of fuzzy membership function allows the model to be easily extended. Some applications may also require other limiting conditions in the form of inequalities.

\section{Conclusions}

The developed mathematical model and computational procedure allows for significant reduction of processing time of $\mathrm{CNC}$ routing operation of solid wood. For typical furniture parts, like the presented commode top, about $50 \%$ decrease of cutting time can be expected. This level of feed rate optimisation requires about tenfold increase of $\mathrm{CNC}$ code size. During sizing of parts, the feed rate is mostly limited by the machine's motor power. In turn, when milling of profile, the only active constraint is surface quality. Generally, application of variable feed rate for wood routing is essential to gain high productivity and to take full advantage of machine capabilities. In the presented approach, the fully optimised $\mathrm{CNC}$ code is generated before actual processing, which does not require any modifications in $\mathrm{CNC}$ control system.

Open Access This article is distributed under the terms of the Creative Commons Attribution License which permits any use, distribution, and reproduction in any medium, provided the original author(s) and the source are credited.

\section{References}

1. Armarego EJ, Smith AJR, Wang J (1993) Constrained optimization strategies and CAM software for single-pass peripheral milling. Int J Prod Res 31(9):2139-2160. doi:10.1080/ 00207549308956849 
2. Asokan P, Saravanan R, Vijayakumar K (2003) Machining parameters optimisation for turning cylindrical stock into a continuous finished profile using genetic algorithm (GA) and simulated annealing (SA). Int J Adv Manuf Technol 21:1-9. doi:10.1007/s001700300000

3. Balic J, Kovacic M, Vaupotic B (2006) Intelligent programming of CNC turning operations using genetic algorithm. J Intell Manuf 17:331-340. doi:10.1007/s10845-005-0001-1

4. Cao SK, Song L, Dong K, Song KF, Sui ZM (2012) Research on path optimization technology for free-form surface five-axis NC machining. Adv Mater Res 443-444:202-208. doi:10.4028/ www.scientific.net/AMR.443-444.202

5. Costes J-P, Ko PL, Ji T, Decès-Petit C, Altintas Y (2004) Orthogonal cutting mechanics of maple: modeling a solid wood-cutting process. J Wood Sci 50:28-34. doi:10.1007/s10086-003-0527-9

6. Cyra G, Tanaka C, Nakao T (1996) On-line control of router feed speed using acoustic emission. Prod J 46(11/12):27-32

7. Cyra G, Tanaka T (2000) The effects of wood-fiber directions on acoustic emission in routing. Wood Sci Technol 34:237-252. doi: $10.1007 / \mathrm{s} 002260000043$

8. Gawroński T (2009) Technological process optimization for the pretreatment of solid wood furniture elements. Prod J 59(5):63-68

9. Goldberg DE (1989) Genetic algorithms in search, optimization, and machine learning

10. Iskra P, Hernández RE (2010) Toward a process monitoring and control of a CNC wood router: development of an adaptive control system for routing white birch. Wood Fiber Sci 42(4):523-535

11. Iskra P, Tanaka C (2005) The influence of wood fiber direction, feed rate, and cutting width on sound intensity during routing. Holz Roh- Werkst 63:167-172. doi:10.1007/s00107-0040541-7

12. Kopecký Z, Peršin M, Zbieć M (2006) Energy conditions of compacted wood. Ann Wars Agric Univ SGGW-AR, For Wood Technol 58:424-429

13. Li ZZ, Zhang ZH, Zheng L (2004) Feedrate optimization for variant milling process based on cutting force prediction. Int $\mathrm{J}$ Adv Manuf Technol 24:541-552. doi:10.1007/s00170-003-1700-4

14. Manav C, Bank HS, Lazoglu I (2011) Intelligent toolpath selection via multi-criteria optimization in complex sculptured surface milling. J Intell Manuf 25:541-552. doi:10.1007/s10845-011-0596-3

15. Masood SH, Lau A (1997) A CAD/CAM system for the machining of precision cams using a half angle search algorithm. Int $\mathrm{J}$ Adv Manuf Technol 14:180-184. doi:10.1007/BF01188413

16. de Moura LF, Hernández RE (2007) Characteristics of sugar maple wood surfaces machined with the fixed-oblique knife pressure-bar cutting system. Wood Sci Technol 41:17-29. doi:10.1007/s00226-006-0074-9

17. Ohuchi T, Murase Y (2006) Milling of wood and wood-based materials with a computerized numerically controlled router V: development of adaptive control grooving system corresponding to progression of tool wear. J Wood Sci 52:395-400. doi:10.1007/s10086-005-0779-7

18. Orlicz T (1970) Obrobka drewna narzedziami tnacymi (processing of wood with cutting tools - in Polish). SGGW, Warsaw
19. Palmqvist J, Lenner M, Gustafsson S-I (2005) Cutting-forces when up-milling in beech. Wood Sci Technol 39:674-684. doi:10. 1007/s00226-005-0010-4

20. Prakash S, Palanikumar K, Manoharan N (2009) Optimization of delamination factor in drilling medium-density fiberboards (MDF) using desirability-based approach. Int J Adv Manuf Technol 45:370-381. doi:10.1007/s00170-009-1974-2

21. Raju KVMK, Janardhana GR, Kumar PN, Rao VDP (2011) Optimization of cutting conditions for surface roughness in CNC end milling. Int $J$ Precis Eng Manuf 12:383-391. doi:10.1007/s12541-011-0050-7

22. Rawangwong S, Chatthong J, Rodjananugoon J (2011) The study of proper conditions in face coconut wood by CNC milling machine international. In: Conference on quality and reliability (ICQR), 14-17 Sept., Bangkok, pp 455-459

23. Saravanan R, Siva Sankar R, Asokan P, Vijayakumar K, Prabhaharan $G$ (2005) Optimization of cutting conditions during continuous finished profile machining using non-traditional techniques. Int $\mathrm{J}$ Adv Manuf Technol 26:30-40. doi:10.1007/s00170-003-1938-x

24. Staniszewska A, Zakrzewski W (1997) Obrobka cieciem (Cutting of wood-in Polish). Wydawnictwo Akademii Rolniczej im. Augusta Cieszkowskiego w Poznaniu, Poznań

25. Sun Y, Li D, Ren F, Guo D (2008) Predictive force model based variable feedrate scheduling for high-efficiency NC machining. In: Xiong $\mathrm{C}$ et al (eds) ICIRA 2008, Part II, LNAI 5315, pp 1076-1085. doi:10.1007/978-3-540-88518-4_115

26. Supadarattanawong S, Rodkwan S (2006) An investigation of the optimal cutting conditions in Parawood (Heavea Brasiliensis) machining process on a CNC Wood router. Kasetsart J (Nat Sci) 40:311-319

27. Tandon V, El-Mounayri H, Kishawy H (2002) NC end milling optimization using evolutionary computation. Int $\mathrm{J}$ Mach Tool Manuf 42:595-605. doi:10.1016/S0890-6955(01)00151-1

28. Veeramani D, Gau Y-S (1995) Analytical models for optimal NC machining of regular convex polygonal pockets. Comput Ind Eng 29(1-4):663-667. doi:10.1016/0360-8352(95)00152-Q

29. Vosniakos GC, Tsifakis A, Benardos P (2006) Neural network simulation metamodels and genetic algorithms in analysis and design of manufacturing cells. Int J Adv Manuf Technol 29(56):541-550. doi:10.1007/s00170-005-2535-y

30. Wang J (1998) Computer-aided economic optimization of endmilling operations. Int J Prod Econ 54:307-320. doi:10.1016/ S0925-5273(98)00008-5

31. Wang J, Armarego EJA (2001) Computer-aided optimization of multiple constraint single pass face milling operations. Mach Sci Technol 5:77-99

32. Wang J, Kuriyagawa T, Wei XP, Guo DM (2002) Optimization of cutting conditions for single pass turning operations using a deterministic approach. Int J Mach Tools Manuf 42:1023-1033

33. Wang ZG, Wong YS, Rahman M (2004) Optimisation of multipass milling using genetic algorithm and genetic simulated annealing. Int J Adv Manuf Technol 24:727-732. doi:10.1007/ s00170-003-1789-5

34. Yildiz AR, Ozturk F (2006) Hybrid enhanced genetic algorithm to select optimal machining parameters in turning operation. In: Proc. IMechE 220 B: J Engng Manuf, pp 2041-2053. doi:10.1243/09544054JEM570 